\title{
Current Concepts in the Management of Osteoporotic Vertebral Fractures: A Narrative Review
}

\author{
Hae-Dong Jang ${ }^{1}$, Eung-Ha Kim ${ }^{1}$, Jae Chul Lee ${ }^{2}$, Sung-Woo Choi ${ }^{2}$, Kyungbum Kim ${ }^{1}$, Byung-Joon Shin ${ }^{2}$ \\ ${ }^{1}$ Department of Orthopaedic Surgery, Soonchunhyang University Bucheon Hospital, Bucheon, Korea \\ ${ }^{2}$ Department of Orthopaedic Surgery, Soonchunhyang University Seoul Hospital, Seoul, Korea
}

Vertebral fractures are the most common type of osteoporotic fracture and can increase morbidity and mortality. To date, the guidelines for managing osteoporotic vertebral fractures (OVFs) are limited in quantity and quality, and there is no gold standard treatment for these fractures. Conservative treatment is considered the primary treatment option for OVFs and includes pain relief through shortterm bed rest, analgesics, antiosteoporotic drugs, exercise, and braces. Studies on vertebral augmentation (VA) including vertebroplasty and kyphoplasty have been widely reported, but there is still debate and controversy regarding the effectiveness of VA when compared with conservative treatment, and the routine use of VA for OVF is not supported by current evidence. Although most OVFs heal well, approximately $15 \%-35 \%$ of patients with unstable fractures, chronic intractable back pain, severely collapsed vertebra (leading to neurological deficits and kyphosis), or chronic pseudarthrosis frequently require surgery. Given that there is no single technique for optimizing surgical outcomes in OVFs, tailored surgical techniques are needed. Surgeons need to pay attention to advances in osteoporotic spinal surgery and should be open to novel thoughts and techniques. Prevention and management of osteoporosis is the key element in reducing the risk of subsequent OVFs. Bisphosphonates and teriparatide are mainstay drugs for improving fracture healing in OVF. The effects of bisphosphonates on fracture healing have not been clinically evaluated. The intermittent administration of teriparatide significantly enhanced spinal fusion and fracture healing and reduced mortality risk. Based on the current literature, there is still a lack of standard management strategies for OVF. There is a need for greater efforts through multimodal approaches including conservative treatment, surgery, osteoporosis treatment, and drugs that promote fracture healing to improve the quality of the guidelines.

Keywords: Spine; Osteoporosis; Vertebral augmentation; Neurology; Teriparatide

\section{Introduction}

With the increase in life expectancy, the incidence of osteoporotic fractures has also increased, with vertebral fracture the most common type of osteoporotic fracture. Osteoporotic vertebral fractures (OVFs) are conventionally treated conservatively; however, complicated cases requiring surgery are challenging to address. OVFs are

Received Nov 19, 2020; Revised Nov 23, 2020; Accepted Nov 24, 2020

Corresponding author: Eung-Ha Kim

Department of Orthopaedic Surgery, Soonchunhyang University Bucheon Hospital, 170 Jomaru-ro, Wonmi-gu, Bucheon 14584, Korea

Tel: +82-32-621-5114, Fax: +82-32-621-5018, E-mail: khaki00@schmc.ac.kr 
significant injuries that result in a functional loss in activities of daily living (ADLs), subsequent fracture (fourfold increase), pulmonary-related complications (threefold increase), and increased mortality (15\% increase) [1$3]$. The presence of an OVF is also a strong predictor of morbidity, including back pain, spinal deformity (such as kyphosis, kyphoscoliosis, and loss of vertebral height), and a reduced quality of life (QOL) [4]. The only published clinical practice guidelines were developed by the American Academy of Orthopedic Surgeons, and of the 11 recommendations, only one has strong evidence (one has moderate evidence) backing it; nine recommendations are weak or inconclusive [5]. In 2017, an overview of the clinical guidelines for OVF noted that the diagnostic and therapeutic recommendations were generally inconsistent. The best management guidelines for OVF are limited in quantity and quality, and there are few level I studies available for review. Greater efforts therefore need to made to improve the quality of the guidelines [6-10]. The aim of this review is to provide an up-to-date overview of the current evidence on the management of OVF. Considering the incidence of OVF, this review focused on the OVF of the thoracic and lumbar spine. (Cervical OVFs were not included.)

\section{Conservative Treatment}

Acute pain from a new OVF usually resolves within 6-12 weeks [11]. Conservative treatment for acute OVF is considered the primary treatment option and focuses on pain relief through short-term bed rest, analgesics, antiosteoporotic drugs, exercise (physiotherapy), and braces (spinal orthosis). Especially in medically underserved areas and low to middle-income settings, conservative treatment is particularly useful and should be actively performed $[12,13]$. Although there are no definitive conclusions in the conservative management of these fractures, this option has remained an effective initial treatment strategy.

\section{Pain management}

Pain management using analgesics is the first-line treatment for patients with OVF and includes acetaminophen, tramadol, codeine, nonsteroidal anti-inflammatory drugs (NSAIDs), opioids, antiosteoporotic drugs, and antidepressants [14]. NSAIDs have the risk of gastrointestinal bleeding, renal toxicity, and cardiovascular events, espe- cially in patients with hypertension and coronary artery disease [15]. Several meta-analyses and cohort studies have discussed the association between the use of NSAIDs and impaired bone healing, with the subsequent risk of nonunion [16]; however, no definitive conclusions have been reached. Opioids such as oxycodone may be used in combination with paracetamol for patients who do not achieve proper pain management through first-line drugs. Opioids not only have dramatic effects on acute pain control but also significant adverse effects, including addiction, reduced gastrointestinal motility, decreased respiratory function, cognitive deficits, loss of balance, increased falls, and depression [17]. Antiosteoporotic drugs may be used for pain control in OVF and include classical antiresorptive agents such as intravenous bisphosphonates and anabolic agents [18]. In meta-analyses, teriparatide (an injectable parathyroid hormone) significantly reduced back pain and the risk of subsequent fracture, and increased bone mineral density [19]. Calcitonin is advisable, however, there is still a lack of evidence to support its usefulness for chronic back pain in OVF [20].

\section{Braces (spinal orthosis)}

Patients with OVF have typically been advised to use a classical three-point contact brace, hyperextension orthosis, an alternative Jewett brace, or a thoracolumbar sacral orthosis brace [21,22]. Braces have numerous advantages such as less invasiveness, lower risk, and cost-effectiveness and are designed to reduce pain and fatigue by preventing postural forward flexion, enabling faster mobilization, and promoting fracture healing through stabilization [21,23]. A prospective randomized study reported the significant effects of a thoracolumbar sacral orthosis brace, including reduced pain and improved trunk muscle strength, posture, body height, QOL, and ADLs [24]. However, the efficacy of a spinal orthosis has generally been based on evidence from studies on patients with non-OVFs [25]. Spinal orthosis has certain disadvantages such as sores, reduced pulmonary capacity, inadequate immobilization, poor compliance, and weakening of the core musculature [26]. There is insufficient information on the specific types of braces, indications, and time to remove [23]. Given the lack of high-quality evidence for spinal orthosis, the strength of recommendations for orthoses for patients with OVF remains weak $[5,21]$. 


\section{Exercise or physiotherapy}

Once the acute pain subsides, core muscle exercise is often recommended to strengthen the back extensors, reduce the chronic pain, and improve the overall posture, gait, QOL, and bone quality [27]. The exercise can also help decrease edema, the use of analgesics for pain management, and the risk of subsequent falls and fractures. In a large nationwide population-based cohort study, continuous regular physical activity was associated with a significantly reduced risk of hip and vertebral fractures [28]. Among the various types of exercise, patients are advised to perform back extension exercises, which have significant effects on fracture prevention, rather than flexion exercises (89\% versus 16\%) [29]. In their consensus statement, the International Osteoporosis Foundation also recommended that patients with osteoporosis engage in a multicomponent exercise program and not to engage in aerobic training without resistance or balance training [30]. However, there is still controversy regarding the use of exercise and physiotherapy for managing OVF, and more research is needed to determine how to optimize their therapeutic value [22]. In 2018, the American Society for Bone and Mineral Research (ASBMR) Task Force Report stated that "exercise may improve mobility and reduce pain and fear of falling. It is uncertain whether exercise improves balance, back extensor strength, reduces falls, and was safe" [31].

\section{Vertebral Augmentation}

Studies on vertebral augmentation (VA), including vertebroplasty and kyphoplasty, have been widely reported. More than 4,000 articles have been published on vertebroplasty alone, and 14 randomized control trials have been published examining the role of VA. However, there is still debate and controversy regarding the effectiveness of VA compared with conservative treatment, specifically for patients with osteoporosis. Although drawing definite conclusions is difficult, VA is generally considered to show an effect in reducing pain during acute periods.

Several studies have suggested the advantages of VA in the early stages of its introduction. VA can be performed under local anesthesia, mechanical stabilization is possible by injecting cement, and pain-related nerve endings can be damaged by the thermal reaction of polymethyl methacrylate (PMMA) cement, resulting in an analgesic effect [32]. Several studies have shown that alleviation of local kyphosis and pain through VA might have greatly contributed to the improvement in sagittal imbalance in osteoporotic vertebral compression fractures (OVCFs) [33]. American spine intervention societies have presented positioning statements emphasizing the advantages of VA and have highlighted the numerous adverse effects of bed rest (e.g., decreased muscle strength, increased pressure sores, deep vein thrombosis, and gastrointestinal and genitourinary complications) [34]. Several studies have addressed osteoporotic burst fractures $(\mathrm{OBF})$, with one reporting satisfactory results with VA in patients with OBF and poor general condition but with no neurologic deficit [35]. Short-segment fixation with cement augmentation (a hybrid technique) has also been reported as an alternative option for OBF [36]. However, given that these studies were conducted with limited surgical indications, routine VA performed without a close examination for unstable OVF might result in serious complications. VA should be applied after sufficiently assessing the patient's general condition and radiological status. Several papers have suggested VA as a treatment option for patients with an intravertebral cleft or vertebral osteonecrosis due to nonunion; however, other articles have reported a high failure rate (Fig. 1) [37], due to the fact that vertebral instability is a determinant factor for inducing pain and perhaps the predominant factor for a delayed neurologic deficit in patients with OVF and an intravertebral cleft. These findings indicate that treatment for instability is important [38]. Despite several studies suggesting the advantages of VA, the critical reason for the lack of acceptance of the evidence is the significant heterogeneity among these trials, resulting in difficulty in translating the results to routine clinical practice.

Although low complication rates have generally been reported for VA, the potentially serious nature of these complications needs to be addressed. The calculated critical complication rate was approximately $2 \%$ for kyphoplasty versus $3.9 \%$ for vertebroplasty [39]. Five trials (821 cases of vertebroplasty) with moderate-quality evidence noted the risk of serious adverse effects including osteomyelitis, cord compression, thecal sac injury, pulmonary artery embolism, and respiratory failure. Cement extravasation is a representative serious complication, which in a retrospective review of 473 VA cases, showed high rates of local leakage (almost asymptomatic, with $87.5 \%$ for vertebroplasty and $49.2 \%$ for kyphoplasty) [40]. Two 

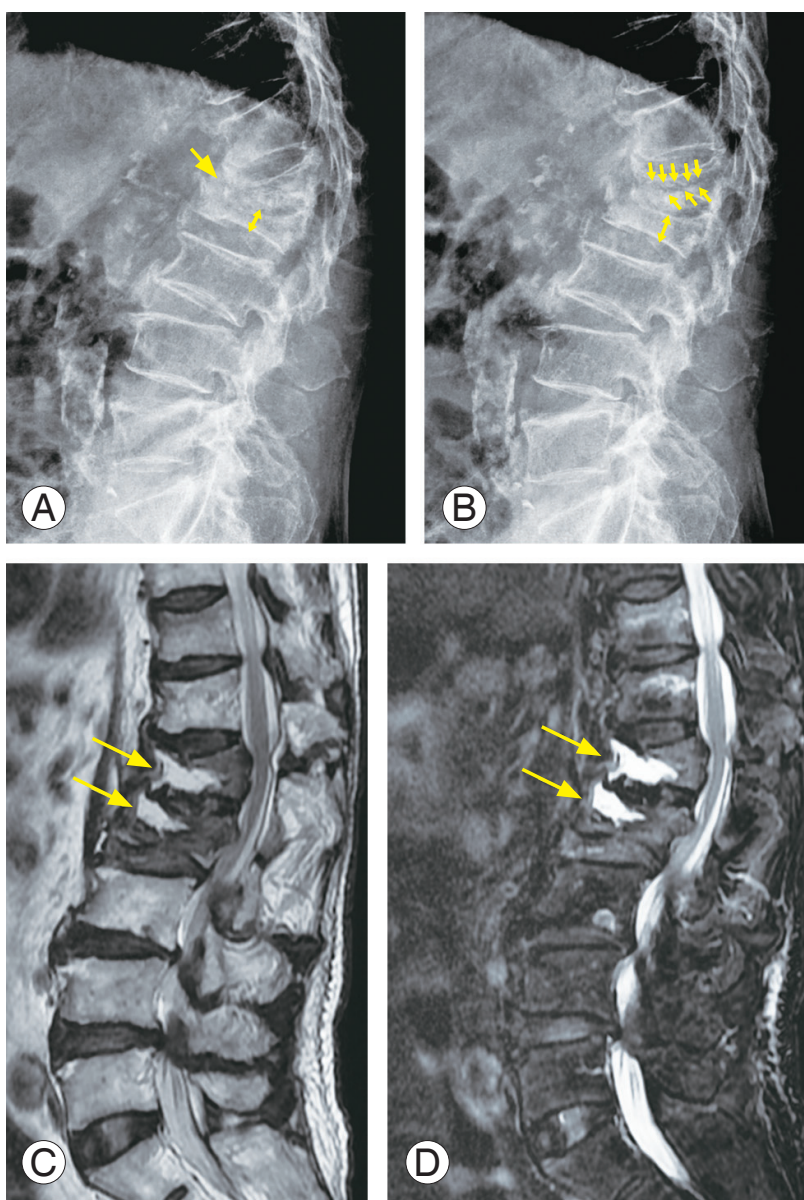

Fig. 1. An 84-year-old male with multiple osteoporotic vertebral fractures at T11, T12, L1, and L2. (A) Plain radiograph in flexion position (yellow arrows). (B) Plain radiograph in extension position. Dynamic radiographs of the patient show a significant vertebral collapse (L1 and L2) and intravertebral instability at the cleft site (yellow arrows). (C) Sagittal MR image (T2-weighted) of lumbar spine display localized intravertebral high-signal intensities (yellow arrows) in L1 and L2 body. (D) Sagittal MR image (fat-suppressed T2-weighted) show intraosseous fluid collections (yellow arrows) at the cleft sites. MR, magnetic resonance.

meta-analyses calculated the symptomatic leakage rate of kyphoplasty at $0 \%-0.3 \%$ compared with $1.6 \%-3.0 \%$ for vertebroplasty [41]. To reduce the risk of cement leakage, several measures have been recommended: (1) meticulous evaluation of preoperative images, (2) a total injected cement volume less than or equal to the void created by the balloon, (3) careful injection of a small volume of cement $(0.2-0.5 \mathrm{~mL})$, (4) frequent assessment by fluoroscopy, (5) high-viscosity cement in a doughy state, and (6) a typical injection time of 3-4 minutes after cement mixing [35].

Another concern are re-fractures at the index level of VA or subsequent fractures at the adjacent level [42]. The following factors have been suggested as related to index level re-fracture: preoperative intravertebral cleft and severe kyphosis, thoracolumbar OVF, solid lump cement distribution pattern, and higher vertebral height restoration [43]. Adjacent-segment fracture (ASF) is a frequently observed complication, with a risk of $2 \%-23 \%$ in kyphoplasty and up to $52 \%$ in vertebroplasty, and most cases of ASF occur within 2 months after VA [44]. In contrast, the rate of recurrent or subsequent fractures ranges from $12 \%$ to $20 \%$ after conservative treatment [44]. The possible reasons for the increased rate of ASF include increased stiffness of the cemented vertebra, which can induce biomechanical change, resulting in 35 -fold harder and 12 fold stiffer cementing than in control groups. Decreased spinal motion and load failure can cause $19 \%$ bone loss in the adjacent level than when adjacent to a nonaugmented vertebra. Unusual loading distribution can increase adjacent level pressure (13\%-18\%) [45]. Until recently, there has been a lack of information regarding the effects of VA on subsequent ASF. A number of authors have suggested that restoring sagittal balance and physiologic loading by VA could reduce the ASF and that the major cause of ASF was underlying osteoporosis and abnormal mechanical load due to spinal deformity [46]. While still controversial, it is reasonable to assume that the effects of VA on subsequent fracture risk are unclear. To overcome ASFs, prophylactic vertebroplasty of the adjacent level has been attempted, based on the results of several studies that suggested building a gradient in mechanical properties through cement injection for adjacent levels [47,48]; however, the preventive effects of this approach have not been fully verified.

After the publication of randomized studies in 2009 showing no superiority of VA over a sham procedure $[7,8]$, several studies disputing the beneficial effects of VA have been reported. Debate and widespread concern have also been raised regarding the design and execution of these studies [49]. In 2018, the ASBMR Task Force Report stated that because the role of VA in both acute and chronic fractures has been controversial, the routine use of VA is not supported by current evidence. When VA is offered, patients should be fully informed about the evidence [31].

When summarizing the results of the studies to date, the effects of VA are inconclusive. VA should only be applied to selected patients who do not respond to conservative treatment and it needs to be carefully performed to achieve initial pain management while considering potentially serious complications. Until better evidence becomes available, the potential benefits of VA remain un- 
proven, and VA should not be routinely offered to patients with OVF.

\section{Surgical Treatments}

Although most OVFs heal well, approximately 15\%-35\% of patients can develop persistent pain, poor chest function, deformity, and neurological deficit requiring surgery [50].

\section{Surgical indication}

Surgery is advised for patients with unstable fractures, continued intractable back pain, chronic pseudarthrosis, and severely collapsed vertebra that lead to neurological deficit and kyphosis. Surgery may also be performed due to a delayed neurologic deficit [51,52]. Incomplete or delayed neurological deficits are believed to be the results of progressive kyphosis or dynamic instability causing repeated microtrauma [51,52]. Dynamic magnetic resonance imaging can be a valuable tool for accurately diagnosing these patients [53].

\section{Surgical methods}

Given that perioperative complications and implant failures have been observed in $18.1 \%$ and $41.2 \%$ of cases, respectively, specific surgical strategies for OVF are needed [54]. There are five typical surgical fusion techniques: anterior spinal fusion, posterior spinal fusion, combined anterior and posterior spinal fusion, posterior three-column osteotomy including shortening osteotomy or vertebral column resection, and vertebroplasty with posterior spinal fusion. In comparative studies, all five procedures resulted in acceptable neurological restoration and functional improvement in walking ability. The complication rates, prevalence of instrumentation-related mechanical failure, and subsequent vertebral fracture were also similar [55]. Thoracotomy, costotransversectomy, retroperitoneal approach, posterolateral fusion, corpectomy, and structural bone graft or cage insertion can also be helpful [56]. The most commonly used posterior instrumentation has the possibility of implant failure due to a flexion moment during standing and sitting, according to the load sharing concept in patients with OVF, and therefore requires longer instrumented fusion constructs and pedicle screw fixation (PSF) concomitant with additional anchors [55].
Numerous authors have recently reported using minimally invasive surgery for OBFs, combining kyphoplasty with or without short-segment PSF, the so-called hybrid stabilization [57]. Although this approach can effectively shorten the entire level of instrumentation and help minimize surgical trauma, surgeons should consider the PMMA cement-related complications, such as cement leakage and embolic insults [27].

\section{Surgical strategies and techniques}

\section{1) Screw characteristics}

A larger diameter screw can increase the pullout strength, with $8-\mathrm{mm}$ diameter screws showing greater pullout strength than 6-mm diameter screws with cement augmentation [58]. However, osteoporotic bone conditions should be considered when performing PSF in patients with OVF. The thin cortex of the pedicle of patients with OVF can eliminate the increased fixation strength by larger diameter screws and increase the risk of pedicle fracture, especially when the screw diameter exceeds $70 \%$ of the pedicle diameter [59]. Increasing screw length also increases screw pullout strength, although this effect can be less pronounced in patients with OVF [60].

\section{2) Screw fixation techniques}

The placement and number of inserted pedicle screws can influence the surgical outcomes of OVF. Pedicle screws inserted with triangulation in the axial plane and engaging the subchondral bone in the sagittal plane can provide superior fixation strength and resist screw pullout [61]. A number of authors have recommended including at least three fixation points above and below the apex of the deformity [62], as this can dissipate the stress and decrease the concentration of stress at any one site; however, the optimal fusion length is still controversial. Undertapping the pedicle (by $1 \mathrm{~mm}$ ) can also enhance the screw purchase [63].

\section{3) Bone-screw interface}

The bone-screw interface is crucial for pullout strength, and there has been extensive research into cement augmentation (with or without screw fenestration) and expandable pedicle screws (Fig. 2) [64,65]. PMMA bone cement (two-fold to three-fold increase in pullout strength) and hydroxyapatite cement are representative pedicle augmentation materials [66]. As with VA pro- 
cedures, surgeons should be aware of the complications related to PMMA cement leakage. Cement insertion in a viscous, doughy state, with an inadequate quantity (at least 2-3 mL per screw) using the standard kyphoplasty cement inserter can reduce the adverse effects. Although hydroxyapatite cement augmentation is potentially safe and effective as an alternative to PMMA, studies on its use in patients with OVF patients are limited. The disadvantage of non-PMMA cement is that it requires 4-24 hours to reach maximum stiffness for the bone-screw interface, whereas PMMA achieves immediate stiffness. Expandable pedicle screws such as an expansion peg (a smaller-gauge screw) are considered a new method for improving the bone-screw interface. The expansion peg advances into the slotted portion of the screw, opens up, and spreads, resulting in expansion of screw diameters and a two-fold increase in pullout strength $[67,68]$. Although studies have shown consistent evidence of strong fusion with a limited risk of complications, related research is limited and less widespread. Additional controlled trials and comparative studies are needed to reach a more definitive conclusion.
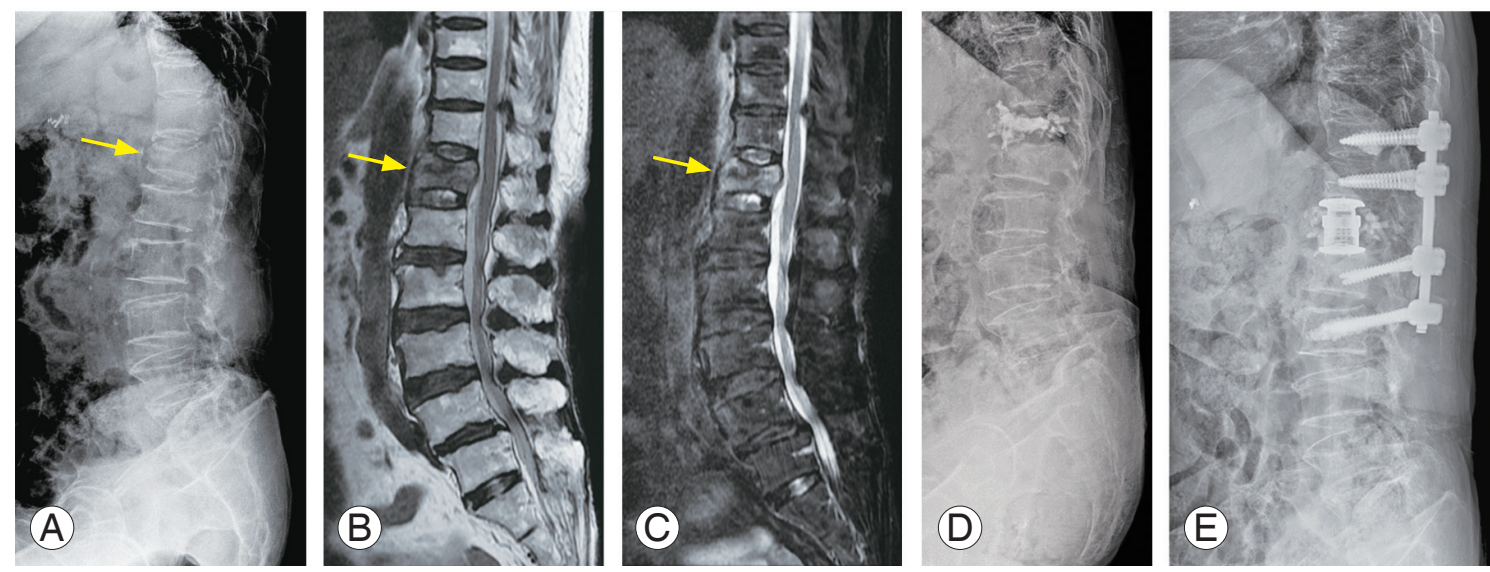

Fig. 2. A 75-year-old female with an osteoporotic vertebral fracture at T12. (A) Plain radiograph shows a decreased vertebral body height at T12 (yellow arrow). (B) Sagittal MR image (T2-weighted) of lumbar spine display high-signal intensities (yellow arrow) in the T12 body. (C) Sagittal MR image (fat-suppressed T2-weighted) shows high-signal intensities (yellow arrow) in the T12 body. (D) Due to progressive kyphosis, vertebral augmentation was performed at another hospital; however, she complained of persistent back pain. (E) We performed combined anterior and posterior spinal fusion including anterior corpectomy, expandable cage insertion, and multilevel pedicle screw fixations with cement augmentation. MR, magnetic resonance.
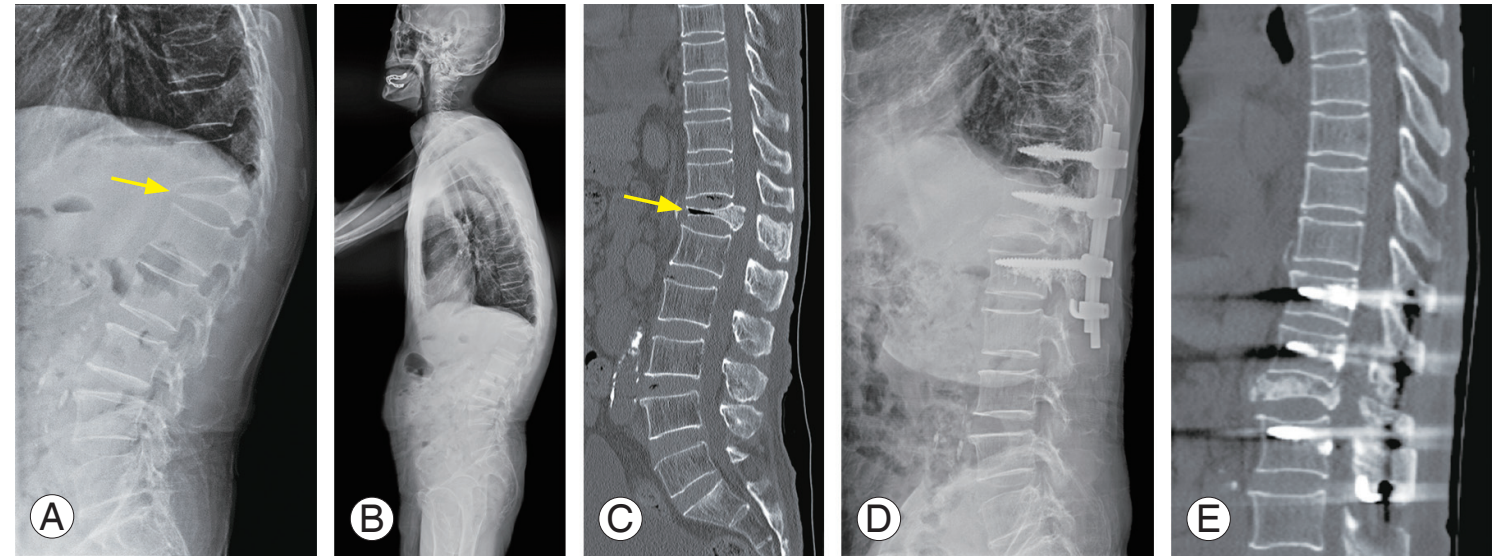

Fig. 3. A 74-year-old male with an osteoporotic vertebral fracture at T12. (A) Plain radiographs show a severely collapsed vertebral body with vertebra plana at T12 (yellow arrow) and marked thoracolumbar kyphosis. (B) Sagittal CT image shows a significant collapse of vertebral body and fragment retropulsed into the spinal canal (yellow arrow) in T12. (C) We performed posterior osteotomy (pedicle subtraction osteotomy) and multilevel pedicle screw fixations with a combination of supplemental offset sublaminar hooks. (D) Postoperative sagittal CT image shows a removal of retropulsed fragment and marked correction of thoracolumbar kyphosis. CT, computed tomography. 
4) Sublaminar wire and hooks

A combination of supplemental offset sublaminar hooks and pedicle screws, also called pediculolaminar fixation, can increase the rigidity and pullout strength by up to $100 \%$ [69]. This method is based on the strong cortex of lamina and the high failure rate of PSF in OVF (Fig. 3). A biomechanical study concluded that PSF should be avoided in patients with a bone mineral density $<0.3 \mathrm{~g} / \mathrm{cm}^{2}$ [70]. The cortices of the laminae are much stronger than the marrow within pedicles of patients with OVF. Given that laminae consist of more cortical bone than cancellous bone, the laminae will less likely be affected by osteoporosis [71]. Sublaminar hooks are therefore considered more resistant to posteriorly directed forces; spinal loop rectangles and sublaminar wiring constructs are also viable options for stabilizing OVF. However, the use of hooks as the sole fixation device should be avoided.

\section{5) Supplementary interbody fusion}

Lumbar interbody fusion techniques can be employed to support the anterior column. However, careful endplate preparation is important to prevent endplate damage, cage subsidence, delayed fusion, or pseudarthrosis. To achieve successful fusion, the use of an appropriate-sized interbody spacer or cage, a large quantity of bone graft, and the meticulous removal of cartilaginous endplate are essential [72].

\section{6) Overall guidelines}

In addition to the methods mentioned above, several authors have suggested numerous techniques for improving the surgical outcomes and reducing the risk of complications in OVF, including bicortical screws, cross-linking, varied fixation equipment, transverse connectors, and modified screw design and trajectories [73,74]. $\mathrm{Hu}[75]$ suggested additional guidelines to contribute to construct rigidity: (1) avoidance of ending the instrumentation within the kyphotic segment to prevent screw loosening and junctional kyphosis, (2) acceptance of an incomplete correction of deformity to prevent hardware pullout from excessive corrective forces, and (3) penetration of the contralateral vertebral body cortex when performing anterior instrumentation. In 2020, advancements in osteoporotic spine fixation were introduced by a comprehensive review article (Table 1) [76].

7) Surgical outcomes and the prognosis

Despite the numerous surgical techniques, achieving suc- cessful outcomes for patients with OVF is excessively difficult. A sagittal imbalance is a reliable and determinant factor related to the prognosis and complications such as junctional failure [77]; however, sagittal balance restored after surgery has not be maintained in all cases. The loss of correction was large in patients with severe comorbidities such as Parkinson's disease, rheumatoid arthritis, and larger correction angles due to severe preoperative local kyphosis and vertebral collapse [78]. Poor postoperative ADLs in patients with OVF were significantly related to the preoperative neurological deficit (graded A-C by the American Spinal Injury Association impairment scale), perioperative complications, and the absence of postoperative parathyroid hormone administration [79].

Since there is no single technique for optimizing sur-

Table 1. A table summarizing the advances in osteoporotic spine fixation

\begin{tabular}{|c|c|}
\hline & $\begin{array}{c}\text { The advances in osteoporotic } \\
\text { spine fixation }\end{array}$ \\
\hline \multirow[t]{9}{*}{ Basic surgical techniques } & Increasing diameter of screw \\
\hline & Increasing length of screw \\
\hline & Small pilot hole \\
\hline & Under tapping of screw track \\
\hline & Longer construct \\
\hline & Supplemental anterior fixation \\
\hline & Use of laminar hooks or wires \\
\hline & Use of transverse connectors \\
\hline & Triangulation techniques \\
\hline \multirow[t]{5}{*}{ Novel surgical techniques } & Cortical bone trajectory \\
\hline & Superior cortical screw technique \\
\hline & Double screw technique \\
\hline & Cross screw trajectory \\
\hline & Bicortical screw technique \\
\hline \multirow[t]{4}{*}{ Novel screw or construct design } & Expandable screws \\
\hline & Fenestrated pedicle screws \\
\hline & Conical screws \\
\hline & Coated screws \\
\hline Cement augmentation & - \\
\hline Prophylactic vertebroplasty & - \\
\hline Perioperative pharmacotherapy & - \\
\hline \multirow[t]{4}{*}{ Other novel strategies } & Biomolecular coating \\
\hline & Novel biomaterials \\
\hline & Biodegradable cements \\
\hline & Combination techniques \\
\hline
\end{tabular}


gical outcomes in patients with OVF, tailored surgical techniques are needed. Surgeons have to pay attention to advancements in osteoporotic spine surgery and should be open to novel thoughts and techniques.

\section{Medical Management in Osteoporotic Vertebral Fractures}

\section{Osteoporosis treatment}

Prevention and management of osteoporosis is the key element in managing OVFs. To reduce the risk of subsequent vertebral fractures, baseline drugs (calcium and vitamin $\mathrm{D}$ ), classical drugs (bisphosphonate and selective estrogen receptor modulators) and newer agents (denosumab and teriparatide) may be administered [80,81].

\section{Medical management of fracture healing}

Bisphosphonates and teriparatide are mainstay medications for improving fracture healing in OVF. Biologically, bisphosphonates increase the fracture callus size during endochondral repair but cause a delay in maturation and have been shown to result in a lower mature fusion mass and a 50\% reduction in bony fusion in animal studies [82]. Authors have suggested that bisphosphonates suppress osteoclast activity and can hinder bone remodeling and maturation in the fracture healing process. However, a randomized trial of 40 patients with osteoporosis showed that bisphosphonate treatment led to a significantly increased interbody fusion rate at 1 year (95\% versus 65\% in the alendronate and control groups, respectively) [83]. The effects of bisphosphonates on fracture healing and spinal fusion have not been clinically evaluated in a metaanalysis or a systematic review [84]. The intermittent administration of teriparatide (recombinant human parathyroid hormone 1-34) induces bone formation through the stimulation of osteoblast proliferation, the prevention of osteoblast apoptosis, and increased osteoblast activity [85]. In animal studies, teriparatide significantly enhanced fusion and fracture healing, and conservative treatment using teriparatide was reported to have comparable results to VA procedures in patients with OVCF. A retrospective comparative study with bisphosphonate showed a significantly higher union rate at 6 months in the teriparatide group and suggested that teriparatide could enhance fracture healing in OVCF [86]. Teriparatide also showed bet- ter results than bisphosphonate in preventing mechanical complications after posterior instrumented fusion for OVF [87].

\section{Conclusions}

Based on the current literature, there is still an obvious lack of standard management strategies for OVFs. To improve the quality of the guidelines, greater efforts are needed through multimodal approaches including conservative treatment, surgery, osteoporosis treatment, and drugs that promote fracture healing.

\section{Conflict of Interest}

The first author (H.D.J.) has received research support funding from the Soonchunhyang University Research Fund. There are no relevant financial activities outside the submitted work to declare. No potential conflict of interest relevant to this article was reported.

\section{Acknowledgments}

This research was funded by Soonchunhyang University Research Fund.

\section{References}

1. Shen M, Kim Y. Osteoporotic vertebral compression fractures: a review of current surgical management techniques. Am J Orthop (Belle Mead NJ) 2007;36:241-8.

2. Jung HJ, Park YS, Seo HY, et al. Quality of life in patients with osteoporotic vertebral compression fractures. J Bone Metab 2017;24:187-96.

3. Kado DM, Browner WS, Palermo L, Nevitt MC, Genant HK, Cummings SR. Vertebral fractures and mortality in older women: a prospective study: study of Osteoporotic Fractures Research Group. Arch Intern Med 1999;159:1215-20.

4. Crans GG, Silverman SL, Genant HK, Glass EV, Krege JH. Association of severe vertebral fractures with reduced quality of life: reduction in the incidence of severe vertebral fractures by teriparatide. Arthritis Rheum 2004;50:4028-34.

5. Esses SI, McGuire R, Jenkins J, et al. The treatment of symptomatic osteoporotic spinal compression frac- 
tures. J Am Acad Orthop Surg 2011;19:176-82.

6. Parreira PCS, Maher CG, Megale RZ, March L, Ferreira ML. An overview of clinical guidelines for the management of vertebral compression fracture: a systematic review. Spine J 2017;17:1932-8.

7. Buchbinder R, Osborne RH, Ebeling PR, et al. A randomized trial of vertebroplasty for painful osteoporotic vertebral fractures. N Engl J Med 2009;361:55768.

8. Kallmes DF, Comstock BA, Heagerty PJ, et al. A randomized trial of vertebroplasty for osteoporotic spinal fractures. N Engl J Med 2009;361:569-79.

9. Klazen CA, Lohle PN, de Vries J, et al. Vertebroplasty versus conservative treatment in acute osteoporotic vertebral compression fractures (Vertos II): an openlabel randomised trial. Lancet 2010;376:1085-92.

10. Wardlaw D, Cummings SR, Van Meirhaeghe J, et al. Efficacy and safety of balloon kyphoplasty compared with non-surgical care for vertebral compression fracture (FREE): a randomised controlled trial. Lancet 2009;373:1016-24.

11. Silverman SL. The clinical consequences of vertebral compression fracture. Bone 1992;13 Suppl 2:S27-31.

12. Ameis A, Randhawa K, Yu H, et al. The Global Spine Care Initiative: a review of reviews and recommendations for the non-invasive management of acute osteoporotic vertebral compression fracture pain in low- and middle-income communities. Eur Spine J 2018;27(Suppl 6):861-9.

13. Haldeman S, Nordin M, Chou R, et al. The Global Spine Care Initiative: World Spine Care executive summary on reducing spine-related disability in low- and middle-income communities. Eur Spine J 2018;27(Suppl 6):776-85.

14. Ensrud KE, Schousboe JT. Clinical practice. Vertebral fractures. N Engl J Med 2011;364:1634-42.

15. Bavry AA, Khaliq A, Gong Y, Handberg EM, CooperDehoff RM, Pepine CJ. Harmful effects of NSAIDs among patients with hypertension and coronary artery disease. Am J Med 2011;124:614-20.

16. Dodwell ER, Latorre JG, Parisini E, et al. NSAID exposure and risk of nonunion: a meta-analysis of case-control and cohort studies. Calcif Tissue Int 2010;87:193-202.

17. Cherasse A, Muller G, Ornetti P, Piroth C, Tavernier C, Maillefert JF. Tolerability of opioids in patients with acute pain due to nonmalignant musculoskeletal disease: a hospital-based observational study. Joint Bone Spine 2004;71:572-6.

18. Pappagallo M, Breuer B, Lin HM, et al. A pilot trial of intravenous pamidronate for chronic low back pain. Pain 2014;155:108-17.

19. Nevitt MC, Chen P, Dore RK, et al. Reduced risk of back pain following teriparatide treatment: a metaanalysis. Osteoporos Int 2006;17:273-80.

20. Knopp-Sihota JA, Newburn-Cook CV, Homik J, Cummings GG, Voaklander D. Calcitonin for treating acute and chronic pain of recent and remote osteoporotic vertebral compression fractures: a systematic review and meta-analysis. Osteoporos Int 2012;23:17-38.

21. Chang V, Holly LT. Bracing for thoracolumbar fractures. Neurosurg Focus 2014;37:E3.

22. Genev IK, Tobin MK, Zaidi SP, Khan SR, Amirouche FML, Mehta AI. Spinal compression fracture management: a review of current treatment strategies and possible future avenues. Global Spine J 2017;7:71-82.

23. Longo UG, Loppini M, Denaro L, Maffulli N, Denaro V. Osteoporotic vertebral fractures: current concepts of conservative care. Br Med Bull 2012;102:171-89.

24. Pfeifer M, Begerow B, Minne HW. Effects of a new spinal orthosis on posture, trunk strength, and quality of life in women with postmenopausal osteoporosis: a randomized trial. Am J Phys Med Rehabil 2004;83:177-86.

25. Dai LY, Jiang LS, Jiang SD. Conservative treatment of thoracolumbar burst fractures: a long-term follow-up results with special reference to the load sharing classification. Spine (Phila Pa 1976) 2008;33:2536-44.

26. Dionyssiotis Y, Trovas G, Thoma S, Lyritis G, Papaioannou N. Prospective study of spinal orthoses in women. Prosthet Orthot Int 2015;39:487-95.

27. Rajasekaran S, Kanna RM, Schnake KJ, et al. Osteoporotic thoracolumbar fractures: how are they different?: classification and treatment algorithm. J Orthop Trauma 2017;31 Suppl 4:S49-56.

28. Han S, Jang HD, Choi S, et al. Changes in physical activity and risk of fracture: a Korean nationwide population-based cohort study. Sci Rep 2020;10:16266.

29. Sinaki M, Mikkelsen BA. Postmenopausal spinal osteoporosis: flexion versus extension exercises. Arch Phys Med Rehabil 1984;65:593-6.

30. Giangregorio LM, Papaioannou A, Macintyre NJ, et al. Too fit to fracture: exercise recommendations for 
individuals with osteoporosis or osteoporotic vertebral fracture. Osteoporos Int 2014;25:821-35.

31. Ebeling PR, Akesson K, Bauer DC, et al. The efficacy and safety of vertebral augmentation: a second ASBMR task force report. J Bone Miner Res 2019;34:321.

32. Denaro V, Longo UG, Maffulli N, Denaro L. Vertebroplasty and kyphoplasty. Clin Cases Miner Bone Metab 2009;6:125-30.

33. Yokoyama K, Kawanishi M, Yamada M, et al. Postoperative change in sagittal balance after kyphoplasty for the treatment of osteoporotic vertebral compression fracture. Eur Spine J 2015;24:744-9.

34. Jensen ME, McGraw JK, Cardella JF, et al. Position statement on percutaneous vertebral augmentation: a consensus statement developed by the American Society of Interventional and Therapeutic Neuroradiology, Society of Interventional Radiology, American Association of Neurological Surgeons/ Congress of Neurological Surgeons, and American Society of Spine Radiology. AJNR Am J Neuroradiol 2007;28:1439-43.

35. Yin P, Li Z, Zhu S, Zhang Y, Su Q, Hai Y. The treatment of osteoporotic thoraco-lumbar burst fractures by unilateral percutaneous kyphoplasty: a prospective observation study. Eur J Pain 2020;24:659-64.

36. Pingel A, Kandziora F, Hoffmann CH. Osteoporotic L1 burst fracture treated by short-segment percutaneous stabilization with cement-augmented screws and kyphoplasty (hybrid technique). Eur Spine J 2014;23:2022-3.

37. Zhang C, Wang G, Liu X, Li Y, Sun J. Failed percutaneous kyphoplasty in treatment of stage 3 Kummell disease: a case report and literature review. Medicine (Baltimore) 2017;96:e8895.

38. Nakamae T, Fujimoto Y, Yamada K, et al. Relationship between clinical symptoms of osteoporotic vertebral fracture with intravertebral cleft and radiographic findings. J Orthop Sci 2017;22:201-6.

39. Bouza C, Lopez T, Magro A, Navalpotro L, Amate JM. Efficacy and safety of balloon kyphoplasty in the treatment of vertebral compression fractures: a systematic review. Eur Spine J 2006;15:1050-67.

40. Lee KA, Hong SJ, Lee S, Cha IH, Kim BH, Kang EY. Analysis of adjacent fracture after percutaneous vertebroplasty: does intradiscal cement leakage really increase the risk of adjacent vertebral fracture? Skeletal
Radiol 2011;40:1537-42.

41. Taylor RS, Taylor RJ, Fritzell P. Balloon kyphoplasty and vertebroplasty for vertebral compression fractures: a comparative systematic review of efficacy and safety. Spine (Phila Pa 1976) 2006;31:2747-55.

42. Lavelle WF, Cheney R. Recurrent fracture after vertebral kyphoplasty. Spine J 2006;6:488-93.

43. Yu W, Xu W, Jiang X, Liang D, Jian W. Risk factors for recollapse of the augmented vertebrae after percutaneous vertebral augmentation: a systematic review and meta-analysis. World Neurosurg 2018;111:11929.

44. Fribourg D, Tang C, Sra P, Delamarter R, Bae H. Incidence of subsequent vertebral fracture after kyphoplasty. Spine (Phila Pa 1976) 2004;29:2270-6.

45. Li YA, Lin CL, Chang MC, Liu CL, Chen TH, Lai SC. Subsequent vertebral fracture after vertebroplasty: incidence and analysis of risk factors. Spine (Phila Pa 1976) 2012;37:179-83.

46. Noriega D, Marcia S, Theumann N, et al. A prospective, international, randomized, noninferiority study comparing an titanium implantable vertebral augmentation device versus balloon kyphoplasty in the reduction of vertebral compression fractures (SAKOS study). Spine J 2020;20:2039-40.

47. Berlemann U, Ferguson SJ, Nolte LP, Heini PF. Adjacent vertebral failure after vertebroplasty: a biomechanical investigation. J Bone Joint Surg Br 2002;84:748-52.

48. Chiang CK, Wang YH, Yang CY, Yang BD, Wang JL. Prophylactic vertebroplasty may reduce the risk of adjacent intact vertebra from fatigue injury: an ex vivo biomechanical study. Spine (Phila Pa 1976) 2009;34:356-64.

49. De Leacy R, Chandra RV, Barr JD, et al. The evidentiary basis of vertebral augmentation: a 2019 update. J Neurointerv Surg 2020;12:442-7.

50. Tsujio T, Nakamura $\mathrm{H}$, Terai $\mathrm{H}$, et al. Characteristic radiographic or magnetic resonance images of fresh osteoporotic vertebral fractures predicting potential risk for nonunion: a prospective multicenter study. Spine (Phila Pa 1976) 2011;36:1229-35.

51. Tamai K, Terai H, Suzuki A, et al. Risk factors for proximal junctional fracture following fusion surgery for osteoporotic vertebral collapse with delayed neurological deficits: a retrospective cohort study of 403 patients. Spine Surg Relat Res 2018;3:171-7. 
52. Nakashima H, Yukawa Y, Ito K, Machino M, Ishiguro N, Kato F. Combined posterior-anterior surgery for osteoporotic delayed vertebral fracture with neurologic deficit. Nagoya J Med Sci 2014;76:307-14.

53. Mallepally AR, Marathe N, Sangondimath G, Das K, Chhabra HS. Posterior stabilization without neural decompression in osteoporotic thoracolumbar fractures with dynamic cord compression causing incomplete neurological deficits. Global Spine J 2020 Oct 6 [Epub]. https://doi.org/10.1177/2192568220956954.

54. Hosogane N, Nojiri K, Suzuki S, et al. Surgical treatment of osteoporotic vertebral fracture with neurological deficit: a nationwide multicenter study in Japan. Spine Surg Relat Res 2019;3:361-7.

55. Watanabe K, Katsumi K, Ohashi M, et al. Surgical outcomes of spinal fusion for osteoporotic vertebral fracture in the thoracolumbar spine: comprehensive evaluations of 5 typical surgical fusion techniques. J Orthop Sci 2019;24:1020-6.

56. Ataka H, Tanno T, Yamazaki M. Posterior instrumented fusion without neural decompression for incomplete neurological deficits following vertebral collapse in the osteoporotic thoracolumbar spine. Eur Spine J 2009;18:69-76.

57. Marco RA, Meyer BC, Kushwaha VP. Thoracolumbar burst fractures treated with posterior decompression and pedicle screw instrumentation supplemented with balloon-assisted vertebroplasty and calcium phosphate reconstruction. Surgical technique. J Bone Joint Surg Am 2010;92 Suppl 1 Pt 1:67-76.

58. Kiner DW, Wybo CD, Sterba W, Yeni YN, Bartol SW, Vaidya R. Biomechanical analysis of different techniques in revision spinal instrumentation: larger diameter screws versus cement augmentation. Spine (Phila Pa 1976) 2008;33:2618-22.

59. Hirano T, Hasegawa K, Takahashi HE, et al. Structural characteristics of the pedicle and its role in screw stability. Spine (Phila Pa 1976) 1997;22:2504-9.

60. Polly DW Jr, Orchowski JR, Ellenbogen RG. Revision pedicle screws: bigger, longer shims: what is best? Spine (Phila Pa 1976) 1998;23:1374-9.

61. Hadjipavlou AG, Nicodemus CL, al-Hamdan FA, Simmons JW, Pope MH. Correlation of bone equivalent mineral density to pull-out resistance of triangulated pedicle screw construct. J Spinal Disord 1997;10:12-9.

62. DeWald CJ, Stanley T. Instrumentation-related com- plications of multilevel fusions for adult spinal deformity patients over age 65: surgical considerations and treatment options in patients with poor bone quality. Spine (Phila Pa 1976) 2006;31(19 Suppl):S144-51.

63. Kuklo TR, Lehman RA Jr. Effect of various tapping diameters on insertion of thoracic pedicle screws: a biomechanical analysis. Spine (Phila Pa 1976) 2003;28:2066-71.

64. McCoy S, Tundo F, Chidambaram S, Baaj AA. Clinical considerations for spinal surgery in the osteoporotic patient: a comprehensive review. Clin Neurol Neurosurg 2019;180:40-7.

65. Lubansu A, Rynkowski M, Abeloos L, Appelboom G, Dewitte O. Minimally invasive spinal arthrodesis in osteoporotic population using a cannulated and fenestrated augmented screw: technical description and clinical experience. Minim Invasive Surg 2012;2012:507826.

66. Shea TM, Laun J, Gonzalez-Blohm SA, et al. Designs and techniques that improve the pullout strength of pedicle screws in osteoporotic vertebrae: current status. Biomed Res Int 2014;2014:748393.

67. Cook SD, Salkeld SL, Stanley T, Faciane A, Miller SD. Biomechanical study of pedicle screw fixation in severely osteoporotic bone. Spine J 2004;4:402-8.

68. Kiyak G, Balikci T, Heydar AM, Bezer M. Comparison of the pullout strength of different pedicle screw designs and augmentation techniques in an osteoporotic bone model. Asian Spine J 2018;12:3-11.

69. Hilibrand AS, Moore DC, Graziano GP. The role of pediculolaminar fixation in compromised pedicle bone. Spine (Phila Pa 1976) 1996;21:445-51.

70. Soshi S, Shiba R, Kondo H, Murota K. An experimental study on transpedicular screw fixation in relation to osteoporosis of the lumbar spine. Spine (Phila Pa 1976) 1991;16:1335-41.

71. Coe JD, Warden KE, Herzig MA, McAfee PC. Influence of bone mineral density on the fixation of thoracolumbar implants: a comparative study of transpedicular screws, laminar hooks, and spinous process wires. Spine (Phila Pa 1976) 1990;15:902-7.

72. Okuda S, Oda T, Miyauchi A, Haku T, Yamamoto T, Iwasaki M. Surgical outcomes of posterior lumbar interbody fusion in elderly patients: surgical technique. J Bone Joint Surg Am 2007;89 Suppl 2 Pt.2:310-20.

73. Park YS, Kim HS, Baek SW, Kong DY, Ryu JA. The effect of zoledronic acid on the volume of the fusionmass in lumbar spinal fusion. Clin Orthop Surg 
2013;5:292-7.

74. Tandon V, Kalidindi KKV, Pacha S, Bhat MR. A prospective study on the feasibility, safety, and efficacy of a modified technique to augment the strength of pedicle screw in osteoporotic spine fixation. Asian Spine J 2020;14:357-63.

75. Hu SS. Internal fixation in the osteoporotic spine. Spine (Phila Pa 1976) 1997;22(24 Suppl):43S-48S.

76. andon V, Franke J, Kalidindi KKV. Advancements in osteoporotic spine fixation. J Clin Orthop Trauma 2020;11:778-85.

77. Lattig F. Bone cement augmentation in the prevention of adjacent segment failure after multilevel adult deformity fusion. J Spinal Disord Tech 2009;22:43943.

78. Nakashima $\mathrm{H}$, Yukawa $\mathrm{Y}$, Ito K, Horie $\mathrm{Y}$, Machino M, Kato F. Combined posteroanterior surgery for osteoporotic delayed vertebral fracture and neural deficit in patients with Parkinson's disease. Orthopedics 2009;32:orthosupersite.com/view.asp?rID=43776.

79. Murata K, Matsuoka $\mathrm{Y}$, Nishimura $\mathrm{H}$, et al. The factors related to the poor ADL in the patients with osteoporotic vertebral fracture after instrumentation surgery. Eur Spine J 2020;29:1597-605.

80. Choi SH, Kim DY, Koo JW, Lee SG, Jeong SY, Kang $\mathrm{CN}$. Incidence and management trends of osteoporotic vertebral compression fractures in South Korea: a nationwide population-based study. Asian Spine J 2020;14:220-8.
81. Kobayashi K, Ando K, Machino M, et al. Persistence of denosumab therapy among patients with osteoporosis. Asian Spine J 2020;14:453-8.

82. Huang RC, Khan SN, Sandhu HS, et al. Alendronate inhibits spine fusion in a rat model. Spine (Phila Pa 1976) 2005;30:2516-22.

83. Nagahama K, Kanayama M, Togawa D, Hashimoto T, Minami A. Does alendronate disturb the healing process of posterior lumbar interbody fusion?: a prospective randomized trial. J Neurosurg Spine 2011;14:500-7.

84. Molvik H, Khan W. Bisphosphonates and their influence on fracture healing: a systematic review. Osteoporos Int 2015;26:1251-60.

85. Dobnig H, Turner RT. Evidence that intermittent treatment with parathyroid hormone increases bone formation in adult rats by activation of bone lining cells. Endocrinology 1995;136:3632-8.

86. Iwata A, Kanayama M, Oha F, Hashimoto T, Iwasaki N. Effect of teriparatide (rh-PTH 1-34) versus bisphosphonate on the healing of osteoporotic vertebra compression fracture: a retrospective comparative study. BMC Musculoskelet Disord 2017;18:148.

87. Kawabata A, Yoshii T, Hirai T, et al. Effect of bisphosphonates or teriparatide on mechanical complications after posterior instrumented fusion for osteoporotic vertebral fracture: a multi-center retrospective study. BMC Musculoskelet Disord 2020;21:420. 